\title{
Seroprevalence of Hepatitis B, Hepatitis C, Syphilis, Human Immunodeficiency Virus and Co-infections among Antenatal Women in a Tertiary care Hospital, Uttar Pradesh, India
}

\author{
Kiran Yadavi ${ }^{1}$, Preeti Verma², Prakash Kumar Mishra ${ }^{3}$, \\ Suresh Kumar Yadav ${ }^{4}$ and Sanjeev Kumar Tripathi ${ }^{1 *}$
}

${ }^{1}$ Department of Microbiology, Government Medical College, Kannauj - 209 732, Uttar Pradesh, India. ${ }^{2}$ Department of Community Medicine, Government Medical College, Kannauj - 209 732, Uttar Pradesh, India. ${ }^{3}$ Deptartment of Microbiology, Jan Nayak Karpuri Thakur Medical College, Madhephura - 852128, Bihar, India. ${ }^{4}$ Department of Pediatrics, Hind Institute of Medical Sciences, Atariya, Sitapur - 261 303, Uttar Pradesh, India.

\begin{abstract}
Sexually transmitted infections (STI) associated with pregnancy poses a great threat to fetal well being due to vertical transmission. This study was conducted to determine the seroprevalence of hepatitis $C$ virus, hepatitis B virus, HIV and syphilis infection in pregnant women. This retrospective study was conducted in Microbiology department over a period of one year from December 2018 to December 2019 at a tertiary care teaching hospital, Uttar Pradesh, India. In this study, hepatitis B surface antigen (HBsAg), antibodies against hepatitis C virus, HIV and syphilis infection were detected in antenatal women. Total 4037 pregnant women attending antenatal clinic were enrolled in this study. The seroprevalence of HBV was $1.34 \%$ (54/4037), HCV was $0.52 \%(21 / 4037)$, syphilis was $0.07 \%$ (3/4037), and HIV was $0.12 \%$ (5/4037). Only one patient had coinfection of HBV and HCV. Regular antenatal screening of all pregnant females for various infections should be done for proper and timely intervention.
\end{abstract}

Keywords: Antenatal clinic, Pregnancy, Sexually transmitted infections, Treponema Pallidum

*Correspondence: sanjeevkgmu@gmail.com; +91 8765533035

(Received: September 12, 2021; accepted: January 12, 2022)

Citation: Yadav K, Verma P, Mishra PK, Yadav SK, Tripathi SK. Seroprevalence of Hepatitis B, Hepatitis C, Syphilis, Human Immunodeficiency Virus and Co-infections among Antenatal Women in a Tertiary care Hospital, Uttar Pradesh, India. J Pure Appl Microbiol. 2022;16(1):435-440. doi: 10.22207/JPAM.16.1.40

(C) The Author(s) 2022. Open Access. This article is distributed under the terms of the Creative Commons Attribution 4.0 International License which permits unrestricted use, sharing, distribution, and reproduction in any medium, provided you give appropriate credit to the original author(s) and the source, provide a link to the Creative Commons license, and indicate if changes were made. 


\section{INTRODUCTION}

Sexually transmitted infections (STI) associated with pregnancy such as HIV, HBV, HCV and syphilis poses a great threat to fetal well being due to vertical transmission.

Hepatitis B infection is very common and important throughout the World. There is an estimated prevalence of 387 million of HBV infected people with approximate 10 million persons getting infected each year. ${ }^{1}$ There are three major routes for transmission of this virus - vertical, horizontal and sexual. ${ }^{2}$ Hepatitis B infection during pregnancy is associated with high rate of vertical transmission which may result in fetal and neonatal hepatitis. The HBV infection acquired in early childhood has high probability to later develop into carrier state and chronic diseases with lethal complications like liver cirrhosis and hepatocellular carcinoma in adults. ${ }^{3}$

Hepatitis $\mathrm{C}$ virus (HCV) comes under flaviviridae family. It is a single stranded RNA virus and mainly causes liver disease. ${ }^{4}$ The prevalence of hepatitis $\mathrm{C}$ virus infection in the asymptomatic people in India ranges from 1.5- 4\%. The vertical transmission in pregnant women occurs in 3-10\%. ${ }^{5}$ Many more studies on the prevalence of hepatitis C infection in pregnant women in India are yet to be done.

Globally, HIV virus prevalence rate was 35 million in 2013. Around 3.2 million infected children were below 15 years of age. ${ }^{6}$ HIV transmission from infected mother to child is around $25-48 \%$ in developing countries which occurs during pregnancy, delivery and breast feeding. The most significant route of transmission in children below 15 years of age is by perinatal transmission. Data from various studies on pregnant women has been used to monitor HIV infection in general population and young children. ${ }^{7}$

Syphilis caused by Treponema pallidum, which is a systemic disease transmitted by sexual route, transfusion of blood and vertical transmission. ${ }^{8}$ It may adversely affect the pregnancy and results in premature births, abortions, still births or various syphilitic stigmatas in born children. ${ }^{9}$

Only a few studies had been done in India to know the seroprevalence of all these infections together in antenatal women. Hence, this study had been done to estimate the prevalence of
HIV, hepatitis $B$, hepatitis $C$, and syphilis infection among antenatal women attending antenatal clinics at our institute. Thus, this study will be helpful to formulate various policies which will play a major role to reduce the spread of these infections.

\section{MATERIALS AND METHODS}

This retrospective hospital record-based study was conducted in Microbiology department at a tertiary care teaching hospital, Uttar Pradesh, India. In this study, hepatitis B surface antigen ( $\mathrm{HBsAg}$ ), antibodies against hepatitis $\mathrm{C}$ virus, HIV and syphilis infection were detected in antenatal women. Data was collected over a period of one year from December 2018 to December 2019 after taking informed consent and following proper ethical guidelines. Total 4037 pregnant women attending antenatal clinic were enrolled in this study.

\section{Laboratory test for $\mathrm{HBsAg}$}

The collected serum samples were screened for HBsAg using HEPALISA (J. Mitra \& Co. Pvt. Ltd., New Delhi, India). It is Enzyme linked immunosorbent assay (ELISA) based on the sandwich principle.

\section{Laboratory test for HCV antibodies}

The serum samples were screened for antibodies against hepatitis $C$ virus using $\mathrm{HCV}$ Microlisa (J. Mitra \& Co. Pvt. Ltd., New Delhi, India). It is a $3^{\text {rd }}$ generation ELISA utilizing combination of various antigens with the sequence of structural and non structural i.e core, E1, E2, NS3, NS4 \& NS5. Laboratory test for Treponema Pallidum

The samples were also screened for syphilis infection by Rapid Plasma Reagin method (RPR). The RPR test (Tulip Diagnostics Pvt. Ltd., Goa, India) is a slide flocculation test using disposable plastic cards for the detection and quantitation of anti lipoidal antibodies.

\section{Laboratory test for HIV}

The samples were screened for HIV-1 and -2 infection using MERISCREEN HIV 1-2 WB test kit (Meril diagnostics Pvt. Ltd., Gujarat, India). All reactive samples were then confirmed by dot immunoassay, COMBAIDS- RS Advantage-ST (Arkray healthcare Pvt. Ltd., Surat, India) and SD HIV 1/2 3.0 (SD Bio standard diagnostics Pvt. Ltd., Haryana, India).

Data was collected in Microsoft office 
excel spreadsheet version 2007 and results were presented in tables and simple percentage and analyzed with chi-square test. $P$ values were calculated and $\mathrm{P}<0.05$ were considered significant.

\section{RESULTS}

A total of 4037 samples from pregnant women were tested for HIV, HBV, HCV and syphilis infection. There were 54 out of 4037 cases, positive for $\mathrm{HBsAg}$ resulting in seroprevalence of $1.34 \%$ (54/4037) (Table 1). Seroprevalence was highest in age group $18-25$ years (65\%) (Table 1$)$. HBV seroprevalence was $50 \%$ in second trimester and $33.3 \%$ in third trimester (Table 2).

There were 21 samples positive for antiHCV out of 4037 cases, resulting in seroprevalence of Hepatitis C virus infection $0.52 \%$. Seroprevalence was highest in age group 18-25 years (62\%) followed by age group $25-30$ years (38\%) (Table 1). HCV seroprevalence was $50 \%$ in the second trimester, 33.3\% in third trimester (Table 2).

Seroprevalence of HIV infection was highest in the age group $25-30$ years (60\%), with overall prevalence rate of $0.12 \%$ (5/4037) (Table 1). HIV seroprevalence in second trimester was $60 \%$ (Table 2).

Three women were positive by RPR with seroprevalence rate of $0.07 \%$ (3/4037). Two cases in the second trimester and 1 case in first trimester were seropositive for syphilis infection (Table 2).

A single case of coinfection of HBV and $\mathrm{HCV}$ noted with co-prevalence rate of $0.02 \%$

Table 1. Prevalence of Hepatitis-B, Hepatitis-C, HIV and Syphilis infections among pregnant women in various age groups

\begin{tabular}{|c|c|c|c|c|c|c|c|c|}
\hline & & $\begin{array}{c}\text { Age } \\
18-25\end{array}$ & $\begin{array}{c}\text { Groups } \\
25-30\end{array}$ & $\begin{array}{c}\text { (in years) } \\
30-35\end{array}$ & $>35$ & Total & Chi-square & $P$ value \\
\hline & Positive & 35 & 13 & 4 & 2 & 54 & & \\
\hline \multirow[t]{3}{*}{ Hep- B } & Negative & 2429 & 1285 & 189 & 80 & 3983 & 2.78 & 0.4 \\
\hline & Total & 2464 & 1298 & 193 & 82 & 4037 & & \\
\hline & Positive & 13 & 8 & 0 & 0 & 21 & & \\
\hline \multirow[t]{3}{*}{ Hep-C } & Negative & 2451 & 1290 & 193 & 82 & 4016 & 1.67 & 0.6 \\
\hline & Total & 2464 & 1298 & 193 & 82 & 4037 & & \\
\hline & Reactive & 2 & 0 & 1 & 0 & 3 & & \\
\hline \multirow[t]{3}{*}{ Syphilis } & Non- Reactive & 2462 & 1298 & 192 & 82 & 4034 & 6.16 & 0.1 \\
\hline & Total & 2464 & 1298 & 193 & 82 & 4037 & & \\
\hline & Reactive & 2 & 3 & 0 & 0 & 5 & & \\
\hline \multirow[t]{2}{*}{ HIV } & Non- Reactive & 2462 & 1295 & 193 & 82 & 4032 & 1.91 & 0.5 \\
\hline & Total & 2464 & 1298 & 193 & 82 & 4037 & & \\
\hline
\end{tabular}

Table 2. Prevalence of Hepatitis-B, Hepatitis-C, HIV and Syphilis infections among pregnant women in various Trimesters

\begin{tabular}{|c|c|c|c|c|c|c|c|}
\hline & & $1 \mathrm{st}$ & $\begin{array}{c}\text { Trimeste } \\
2^{\text {nd }}\end{array}$ & $3^{\text {rd }}$ & Total & Chi-square & $P$ value \\
\hline & Positive & 9 & 27 & 18 & 54 & & \\
\hline \multirow[t]{3}{*}{ Hep- B } & Negative & 1231 & 1596 & 1156 & 3983 & 5.16 & 0.07 \\
\hline & Total & 1240 & 1623 & 1174 & 4037 & & \\
\hline & Positive & 4 & 10 & 7 & 21 & & \\
\hline \multirow[t]{3}{*}{ Hep-C } & Negative & 1236 & 1613 & 1167 & 4016 & 1.35 & 0.5 \\
\hline & Total & 1240 & 1623 & 1174 & 4037 & & \\
\hline & Reactive & 1 & 2 & 0 & 3 & & \\
\hline \multirow[t]{3}{*}{ Syphilis } & Non-Reactive & 1239 & 1621 & 1174 & 4034 & 1.40 & 0.4 \\
\hline & Total & 1240 & 1623 & 1174 & 4037 & & \\
\hline & Reactive & 0 & 3 & 2 & 5 & & \\
\hline \multirow[t]{2}{*}{ HIV } & Non-Reactive & 1240 & 1620 & 1172 & 4032 & 2.23 & 0.3 \\
\hline & Total & 1240 & 1623 & 1174 & 4037 & & \\
\hline
\end{tabular}


Yadav et al. | J Pure Appl Microbiol | 16(1):435-440 | March 2022 | https://doi.org/10.22207/JPAM.16.1.40

Table 3. Comparison of seroprevalence of HBsAg positivity among antenatal cases in different studies

\begin{tabular}{lcccc}
\hline Study & Year & Location & Sample Size & Prevalence rate \\
\hline Present Study & 2018 & Uttar Pradesh & 4037 & $1.34 \%$ \\
Jethava SD et al. & 2017 & Gujarat & 1000 & $0.6 \%$ \\
Sibia P et al. & 2016 & Punjab & 3686 & $1.11 \%$ \\
Mehta KD et al. & 2013 & Gujarat & 1038 & $2.9 \%$ \\
Sehgal A et al. & 1992 & Chandigarh & 4137 & $2.6 \%$ \\
Gupta l et al. & 1992 & Chandigarh & 2337 & $2.5 \%$ \\
\hline
\end{tabular}

Table 4. Comparison of seroprevalence of Anti HBc positivity among antenatal cases in different studies

\begin{tabular}{lcccc}
\hline Study & Year & Location & Sample Size & Prevalence rate \\
\hline Present Study & 2018 & Uttar Pradesh & 4037 & $0.52 \%$ \\
Jethava SD et al. & 2017 & Gujarat & 1000 & $0.2 \%$ \\
Mehta KD et al. & 2013 & Gujarat & 1038 & $0.19 \%$ \\
Parthiban R et al. & 2009 & Tamilnadu & 3115 & $0.6 \%$ \\
Kumar A et al. & 2007 & New Delhi & 8130 & $1.03 \%$ \\
\hline
\end{tabular}

Table 5. Comparison of seroprevalence of HIV antibody positivity among antenatal cases in different studies

\begin{tabular}{lcccc}
\hline Study & Year & Location & Sample Size & Prevalence rate \\
\hline Present Study & 2018 & Uttar Pradesh & 4037 & $0.12 \%$ \\
Jethava SD et al. & 2017 & Gujarat & 1000 & $0.1 \%$ \\
Mehta KD et al. & 2013 & Gujarat & 1038 & $0.38 \%$ \\
Mathur M et al. & 2008 & Mumbai & 2550 & $1.86 \%$ \\
Mustafa M et al. & 2007 & Hyderabad & 3602 & $1.1 \%$ \\
\hline
\end{tabular}

(1/4037). There was no HIV and syphilis coinfection in $\mathrm{HBsAg}$ positive cases.

\section{DISCUSSION}

In the present study, seroprevalence of Hepatitis B infection was $1.34 \%$ among pregnant women, which is similar with the prevalence shown in the study done by Sibia P et al. ${ }^{10}$ (1.11\%). On the contrary, Mehta KD et al. ${ }^{11}$ (2.9\%), Sehgal A et al. ${ }^{12}$ $(2.6 \%)$ and Gupta I et al. ${ }^{13}(2.5 \%)$ reported slightly higher prevalence of HbsAg (Table 3). Regarding prevalence of $\mathrm{HBV}$ infection (3-4\%), India falls into intermediate zone. ${ }^{14}$ The HBV infection acquired in early childhood has more chances to develop into carrier state. Babies who are born to HBV infected mother, $90 \%$ of them become carrier and may develop chronic liver disease and becomes the important source for transmission in community. ${ }^{15,16}$ Therefore, mandatory antenatal screening for $\mathrm{HBsAg}$ is very important to address this problem. Immunoprophylaxis of the babies at risk shortly after birth would help in preventing perinatal transmission. ${ }^{17}$

In this study, 21 out of 4037 samples were positive for $\mathrm{HCV}$ infection $(0.52 \%)$, which is almost similar to prevalence shown in the study done by Parthiban $\mathrm{R}$ et al. ${ }^{18}(0.6 \%)$. On the other hand, Kumar A et al. ${ }^{14}$ reported slightly higher prevalence rate $(1.03 \%)$ in their study. According to the data given by National centre for disease control (NCDC), the seroprevalence of hepatitis $C$ virus infection in India is $1 \%$. HCV is mainly a blood borne pathogen; and there is very high risk of chronicity in it which can lead to serious complications like liver cirrhosis, liver failure and even the malignancy. ${ }^{19} \mathrm{HCV}$ infection among antenatal women may result in various complications like premature contractions, preterm delivery, Gestational diabetes mellitus, vaginal bleeding and mortality. ${ }^{20,21}$ These complications can be prevented to a large extent, if early screening of 
all pregnant women during antenatal checkup and timely management of those cases can be done.

The seroprevalence of syphilis infection in this study $(0.07 \%)$ was less comparable to the prevalence seen in the study by Gupta I et al. ${ }^{13}$ (1.47\%). In India, the prevalence of syphilis in pregnant women remained around $1.5 \%$ between 2003 and 2007. ${ }^{22}$ Perinatal transmission of Treponema pallidum may lead to various complications in outcome of pregnancy like stillbirth, spontaneous abortions, low birth weight babies or congenital syphilis in the baby. The Rapid plasma reagin (RPR), a nontreponemal test has traditionally been used as screening test for syphilis. It is also a quantitative test and antibody titers can be used to monitor treatment response. As RPR is a nontreponemal test, sometimes it can give false positive results which could be confirmed with treponemal specific test such as Fluorescent treponemal antibody absorption test (FTA-ABS) test or Treponema pallidum hemagglutination assay (TPHA). Due to financial constraint this test couldn't be done in this study.

In the present study, seroprevalence of HIV infection came out to be $0.12 \%$ which is similar to study done by Jethava SD et al..$^{23}(0.1 \%)$. The prevalence rate in the present study were lower compared to the prevalence rate in the study done by Mathur Met al. ${ }^{24}$ (1.86\%), Mustafa Met al. ${ }^{25}$ (1.1\%) and Mehta KD et al. ${ }^{11}$ (0.38\%) (Table 5). In this study, we noted lower trend of HIV prevalence. Although limited sample size, in a single hospital cannot be the representative of whole country. Still we can reduce the perinatal transmission of HIV infection by early antenatal screening for HIV infection, giving perinatal chemotherapy and elective caesarean section.

\section{CONCLUSION}

Infection of HBV, HCV, HIV and syphilis is paramount health problem worldwide, requires urgency to take some measures to prevent and control them. Steps should be taken to create awareness among the public to bring about behavioral change in the society. Regular proper antenatal screening for various infections of all the pregnant women should be done. Along with that there should be HBV vaccination of females of reproductive age group on regular basis so that the perinatal transmission rates of these infections can be minimized. Proper preventive and timely interventional measures targeting all the pregnant women should be taken to avoid vertical transmission of these infections to newborns.

\section{ACKNOWLEDGMENTS}

None.

\section{CONFLICT OF INTEREST}

The authors declare that there is no conflict of interest.

\section{AUTHORS' CONTRIBUTION}

All authors listed have made a substantial, direct and intellectual contribution to the work, and approved it for publication.

\section{FUNDING}

None.

\section{DATA AVAILABILITY}

All dataset generated or analysed during this study are included in the manuscript.

\section{ETHICS STATEMENT}

This article does not contain any experimental studies on human participants or animals performed by any of the authors. It was a retrospective study and only case records of patients were accessed and the identity or privacy of the patients were not revealed in the study.

\section{REFERENCES}

1. Drosten C, Nippraschk T, Manegold C, et al. Prevalence of hepatitis B virus DNA in anti-HBc-positive/ HBsAg-negative sera correlate with HCV but not HIV serostatus. J Clin Virol. 2004;29(1):59-68. doi: 10.1016/ S1386-6532(03)00090-8

2. Edmunds WJ, Medley GF, Nokes DJ. The transmission dynamics and control of hepatitis $B$ virus in the Gambia. Stat Med. 1996;30(15):2215-2233. doi: 10.1002/(SICI)1097-0258(19961030)15:20<2215::AIDSIM369>3.0.CO;2-2

3. Sookoian S. Liver disease during pregnancy: acute viral hepatitis; Symposium on liver \& pregnancy. Ann Hepatol. 2006;5(3):231-236. doi: 10.1016/S16652681(19)32019-8

4. Madhava V, Burgess C, Drucker E. Epidemiology of chronic hepatitis $C$ virus infection in Sub Sahara Africa. Lancet Infect Dis. 2002;2(5):293-302. doi: 10.1016/ S1473-3099(02)00264-5

5. Irshad M, Acharya SK, Joshi YK. Prevalence of hepatitis $C$ virus antibodies in the general population and in the 
selected groups of patients in Delhi. Indian J Med Res. 1995;102:162-164. PMID:8543360.

6. Praveena P, Edward S, Kannan L. A study on cognizance of vertical transmission of HIV/AIDS among pregnant women attending antenatal clinic in a tertiary care hospital, Chennai. Int I community Med Public Health. 2016;3(2):408-413. doi: 10.18203/2394-6040. ijcmph20160422

7. Zaba B, Boerma T, White R. Monitoring the AIDS epidemic using HIV prevalence data among young women attending antenatal clinics: prospects and problems. AIDS. 2000;14(11):1633-1645. doi: 10.1097/00002030-200007280-00020

8. Mulu A, Kassu A, Tessema B, Yismaw G, Tiruneh M, Moges $F$ et al. Seroprevalence of syphilis and HIV-1 during pregnancy in a teaching hospital in north west Ethiopia. Jpn J Infect Dis.2007;60(4):193-5. PMID:17642529

9. Chakraborty R, Luck S. Syphilis is on the increase: The implications for child health. Arch Dis Child. 2008;93(2):105-109. doi: 10.1136/adc.2006.103515.

10. Sibia P, Mohi MK, Kumar A. Seroprevalence of hepatitis $B$ infection among pregnant women in one of the institute of northern India. J Clin Diagn Res. 2016;10(8):QC08-QC09. doi: 10.7860/ JCDR/2016/20614.8299

11. Mehta KD, Antala S, Mistry M, Goswami Y. Seropositivity of hepatitis $B$, hepatitis $C$, syphilis and HIV in antenatal women in India. J Infect Dev Ctries 2013;7(11):832-837. doi: $10.3855 /$ jidc. 2764

12. Sehgal A, Gupta I, Sehgal R, Ganguly NK. Hepatitis $B$ vaccine alone or in combination with anti-HBs immunoglobulin in the perinatal prophylaxis of babies born to HBsAg carrier mothers. Acta Virol. 1992;36(4):359-366. PMID: 1362320.

13. Gupta I, Sehgal A, Sehgal R, Ganguly NK. Vertical transmission of hepatitis B in North India. J HygEpid Microbiol Immunol. 1992;36:263-267. PMID: 1293210.

14. Kumar A, Sharma AK, Gupta RK, Kar P, Chakravarti A. Prevalence and risk factors for hepatitis $C$ virus among pregnant women. Indian J Med Res. 2007;126(3):211215. PMID: 18037715.

15. Joshi N, Kumar A. Immunoprophylaxis of hepatitis B virus infection. Indian J Med Microbiol. 2001;19(4):172183. PMID: 17664829.

16. Chakravarti A, Rawat D, Jain M. A study on perinatal transmission of the hepatitis B virus. Indian J Med Microbiol. 2005;23(2):128-130. doi: 10.4103/02550857.16055

17. Hamdani-Belghiti S, Bouazzaou NL. Mother-Child transmission of hepatitis $B$ virus. State of the problem and prevention. Arch Pediatrie. 2000;7(8):879-882. doi: 10.1016/S0929-693X(00)80199-2

18. Parthiban R, Shanmugam S, Velu V, et al. Transmission of hepatitis $C$ virus infection from asymptomatic mother to child in southern India. Int J Infect Dis. 2009;13(6):394-400. doi: 10.1016/j.ijid.2009.01.013

19. National centre for disease control. News Letter.2014;3(1).https://ncdc.gov.in/index1. php lang $=1$ \&level $=2 \&$ sublinkid $=339 \&$ lid $=223$, Accessed on 10 September 2021.

20. Chen SL, Morgan TR. The natural history of hepatitis C virus infection. Int J Med Sci. 2006;3(2):47-52. doi: 10.7150/ijms.3.47

21. Reddick KLB, Jhaveri R, Gandhi M, James AH, Swamy GK. Pregnancy outcomes associated with viral hepatitis. J Viral Hepat. 2011;18(7):e394-e398. doi: 10.1111/j.1365-2893.2011.01436.x

22. World Health Organization. Regional strategy for the elimination of congenital syphilis. 2009. https://www. who.int/iris/handle/10665/205844, Accessed on 10 September 2021.

23. Jethava SD, Shingala HK, Sinha M. Seroprevalence of hepatitis $B$, hepatitis $C$, syphilis and HIV in pregnant women in a tertiary care hospital, Gujarat, India. J Evid Based Med Healthc. 2017;4(62):3707-3711. doi: 10.18410/jebmh/2017/739

24. Mathur M, Taklikar S, Turbadkan D. Study of HIV seroprevalence and sociodemographic pattern in antenatal cases and vertical transmission to neonates. Indian J Med Microbiol. 2008;26(3):289-290. doi: 10.4103/0255-0857.42075

25. Mustafa M, Ahmed KS, Habibullah CM. Prevalence of Human Immunodeficiency Virus Infection in pregnant women. Indian J Med Microbiol. 2007;25(2):172-173. doi: 10.4103/0255-0857.32733 